Article

\title{
Kinetic Analysis and Epitope Mapping of Monoclonal Antibodies to Salmonella Typhimurium Flagellin Using a Surface Plasmon Resonance Biosensor
}

\author{
Devendra Bhandari ${ }^{1}$, Fur-Chi Chen ${ }^{2, * \mathbb{D}}$, Shreya Hamal ${ }^{1}$ and Roger C. Bridgman ${ }^{3}$ \\ 1 Department of Agricultural and Environmental Sciences, Tennessee State University, Nashville, TN 37209, \\ USA; dbhandar@my.tnstate.edu (D.B.); ssinghha@my.tnstate.edu (S.H.) \\ 2 Department of Human Sciences, Tennessee State University, Nashville, TN 37209, USA \\ 3 Hybridoma Facility, Auburn University, Auburn, AL 36830, USA; bridgcr@auburn.edu \\ * Correspondence: fchen1@tnstate.edu; Tel.: +1-615-963-5410
}

Received: 11 February 2019; Accepted: 2 March 2019; Published: 6 March 2019

\begin{abstract}
Salmonella Typhimurium is one of the leading causes of foodborne diseases worldwide. Biosensors and immunoassays utilizing monoclonal antibodies are widely used for the detection and subtyping of $S$. Typhimurium. However, due to insufficient information on the nature of binding with S. Typhimurium flagellin, the selection of appropriate antibodies for assay development is a cumbersome task. Hence, we aimed to compare the binding kinetics of a panel of monoclonal antibodies and their relative binding sites to flagellin antigen using a surface plasmon resonance biosensor. Initially, the flagellin was captured on the sensor surface through an immobilized anti-flagellin antibody. The interactions of different concentrations of monoclonal antibodies to flagellin were determined, and binding curves were fitted using 1:1 bio-interaction model to calculate the kinetic parameters. For epitope mapping, pairwise comparisons were completed to determine the binding inhibition of each paired combination of monoclonal antibodies. It was found that these monoclonal antibodies differed significantly $(p<0.05)$ in association rate, dissociation rate, and equilibrium dissociation constants. Of the five monoclonal antibodies, only two interfered with the binding of each other. Four distinct epitopes located within a $23 \mathrm{kDa}$ domain of flagellin were identified. Findings from this study provide crucial information needed for the further development and optimization of biosensors and other immunoassays for the detection and subtyping of Salmonella.
\end{abstract}

Keywords: Salmonella Typhimurium; flagellin; epitope mapping; kinetic analysis; surface plasmon resonance

\section{Introduction}

Salmonella Typhimurium is one of the leading cause of foodborne diseases worldwide [1]. The bacterium has 6-10 flagella that are arranged peritrichously around the cell for its mobility [2]. A single flagellum is divided into three distinct sub-structures: Hook, basal body, and filament [3]. The filament, which extends to the extracellular space, is up to $10 \mu \mathrm{m}$ long and is composed of approximately 20,000 subunits of a single species of protein called flagellin. S. Typhimurium has two non-allelic genes that encode two antigenically distinct flagellins. The $f l i C$ gene encodes phase 1 flagellin and the $f l j B$ gene encodes phase 2 flagellin [4]. Individual cells produce either phase 1 or phase 2 flagellin by a mechanism called phase variation [5]. Serotype Typhimurium have ' $i$ ' as phase 1 flagellin and ' 1,2 ' as phase 2 flagellin [6], which are identical for the first 71 amino acids and the last 46 amino acids and are antigenically distinct for surface exposed amino acids in the middle portion [7]. Both flagellins have mostly hypervariable regions spanning from 190-291 amino acids where most 
antibodies bind. The binding of monoclonal antibodies with either ' $i$ ' flagellin or ' 1,2 ' flagellin is determined by the specificity of the antibody to ' $i$ ' and/or '1,2' flagellins [8].

In recent years, the production of high-quality antibodies in larger quantities has become easier, especially after the advent of hybridoma technology $[9,10]$. Hybridoma technology has been used extensively to produce different types of antibodies for therapeutic, disease diagnostic, and research purposes [9-14]. Most importantly, various antibodies against Salmonella flagellin were also produced utilizing hybridoma technology [15-19]. The availability of different anti-flagellin antibodies along with the easy extraction of Salmonella flagellin [20] facilitates the development of numerous immunoassays like enzyme-linked immunosorbent assays (ELISA) and Surface Plasmon Resonance (SPR) assays. ELISA detects and quantifies Salmonella flagellin using a labeled antibody. A number of ELISA have been successfully used for the detection of Salmonella from food and environmental samples [21-24]. In addition to ELISA, SPR assays have recently been applied for the detection of Salmonella [25-28]. Similarly, SPR assays developed with numerous anti-flagellin antibodies from various strains of Salmonella have a potential for subtyping Salmonella based on antibody and flagellin binding kinetics [29].

Despite a multitude of applications for anti-flagellin antibodies, the sensitivity of the assays did not improve as expected. The sensitivity and reliability of the assays can be enhanced by using well-characterized antibodies in terms of the binding epitope and binding kinetics. Information about the epitope map facilitates the selection of one or more antibodies based on the objective of the assay to be developed. Especially in the sandwich type assay performed in ELISA and SPR, two antibodies should have different binding sites on the antigen. If the antibodies have the same binding epitope, the detection antibody would fail to give a signal. Similarly, binding kinetics play a vital role in the sensitivity and specificity of the developed immunoassays. The association rate shows how fast antigens bind to an antibody, whereas the dissociation rate shows how fast the binding disrupts. More importantly, affinity, which is inversely related to the equilibrium dissociation constant, indicates how much antibody-antigen complex is formed at the equilibrium. Knowledge of association rate, dissociation rate, and affinity between flagellin and anti-flagellin antibodies benefits the selection of appropriate antibodies in assay development.

The SPR optical biosensor works on the principle of total internal reflection and measures the antibody-antigen interaction in terms of change in the reflective angle [30]. SPR assays are fast, label-free, and allow real-time monitoring of the biomolecular interactions with higher sensitivity [31]. In contrast to covalent immobilization, the capture-based antibody immobilization on the SPR sensor chips allows for improved orientation, and thus the reactivity potential of the antibody is increased as compared with most ELISA, where the antibody is physically adsorbed on the microplate [32]. Due to these advantages, SPR provides better epitope mapping alternatives over commonly used ELISA methods. SPR has been extensively used for epitope mapping of different antibodies [33-37]. Similarly, kinetic analyses of different antibodies with their respective antigens were successfully accomplished with SPR biosensors [38-45].

In this study, we have developed an SPR assay using the capture-based immobilization to determine the relative binding sites of five monoclonal antibodies to $S$. Typhimurium flagellin. Additionally, we have investigated the binding kinetics of these monoclonal antibodies using the same approach.

\section{Materials and Methods}

\subsection{Materials and Equipment}

Salmonella Typhimurium (ATCC 13311) was purchased from American Type Culture Collection (Manassas, VA, USA), and stored at $-80^{\circ} \mathrm{C}$ before use.

Tryptic soy agar (TSA) and tryptic soy broth (TSB) were supplied by Remel, Thermo Fisher Scientific Inc. (Lenexa, KS). 10× phosphate buffered saline (PBS), Tween 20, $4 \times$ XT sample buffer, 
$20 \times$ XT reducing agent, Trans-Blot ${ }^{\circledR T}$ Turbo ${ }^{\mathrm{TM}}$ RTA Mini Nitrocellulose Transfer Kit, Precision Plus Protein $^{\mathrm{TM}}$ WesternC ${ }^{\mathrm{TM}}$ Standard, Precision Protein ${ }^{\mathrm{TM}}$ Strep Tactin-HRP conjugate, Goat Anti-Mouse HRP conjugate and Clarity Western ECL substrate were acquired from Bio-Rad Laboratories, Inc. (Hercules, CA, USA). Bovine serum albumin (BSA) was bought from Fisher Scientific (Hampton, NH). Lyophilized trypsin powder was purchased from Sigma-Aldrich Co. (St. Louis, MO). Bolt ${ }^{\mathrm{TM}} 4-12 \%$ Bis-Tris Plus gels were purchased from Life Technologies (Carlsbad, CA). The $1 \times$ PBS with 0.05\% Tween 20 (PBST) was used as a working buffer. Primary and secondary antibodies were diluted in PBST containing $1 \%$ BSA.

$\mathrm{N}$-(3-dimethylaminopropyl)-N'-ethylcarbodiimide hydrochloride (EDC), N-hydroxysuccinimide (NHS), ethanolamine hydrochloride, and sodium acetate were acquired from Sigma-Aldrich Inc (St. Louis, MO, USA). All solutions were prepared using distilled, deionized, filtered and degassed water.

SPR assays were performed using a Reichert SR7500 DC biosensor and its associated software called Integrated SPR Autolink Version 1.1.14-T (Reichert Technologies, Buffalo, NY, USA). TraceDrawer Version 1.6.1 by Ridgeview Instruments AB (Upsala, Sweden) was used to process and analyze SPR data. The 500 kDa Carboxymethyl Dextran Hydrogel Surface Sensor Chip (SR7000 gold sensor slide) was purchased from Reichert Inc, NY, USA.

\subsection{Preparation of Salmonella Typhimurium Flagellin}

Cultures of S. Typhimurium were prepared on TSA plates by incubating at $35^{\circ} \mathrm{C}$ for $24 \mathrm{~h}$ after retrieving from the freezer. The cultrues were further propagated by transferring to additional TSA plates. Cells from each plate after incubating at $35^{\circ} \mathrm{C}$ for $24 \mathrm{~h}$ were collected by washing with $1 \mathrm{~mL}$ PBS. The recovered suspensions were centrifuged $(3000 \times \mathrm{g}, 10 \mathrm{~min})$ and the cell pellets were collected. A volume of $10 \mathrm{~mL}$ of $250 \mathrm{mM}$ Glycine- $\mathrm{HCl}, \mathrm{pH} 2.0$, was added to the pellets and then vortexed. After incubating the suspension for $30 \mathrm{~min}$ at room temperature, centrifugation was done to collect the supernatant. The $\mathrm{pH}$ of the supernant was adjusted to 7.0, and an Amicon®Ultra-15, 10K centrifugal filter was used to concentrate and to exchange buffer to PBS. Finally, the sample from the filter was collected and the volume was adjusted to $500 \mu \mathrm{L}$ using PBS. The flagellin preparations were analyzed using Bolt ${ }^{\mathrm{TM}} 4-12 \%$ Bis-Tris Plus gels to check for purity. Presence of minor fragments in the flagellin preparation was noticed and described in Section 3.1. The flagellin preparations were stored at $-80^{\circ} \mathrm{C}$ and later retrieved for antibody production.

\subsection{Production of Anti-Flagellin Antibodies}

Flagellin preparation $(1.0 \mathrm{mg} / \mathrm{mL})$ in PBS containing $0.3 \%$ of sodium dodecyl sulfate was heated in boiling water for $10 \mathrm{~min}$. Four BALB/c mice (7-10 weeks old) were immunized either subcutaneously or intraperitoneally with $0.15 \mathrm{mg}$ of the heat-treated flagellin mixed 1:1 $(v / v)$ with Freund's complete adjuvant followed by two booster injections at 4-week intervals with $0.1 \mathrm{mg}$ per mouse of flagellin mixed 1:1 $(v / v)$ with Freund's incomplete adjuvant. Test sera were collected by tail bleeding 10 days after each injection; the titer of the sera against the flagellin preparation was then determined by indirect ELISA. The mouse exhibiting the highest serum titer to flagellin then received a final boost of $0.1 \mathrm{mg}$ of the flagellin in PBS four days before the fusion. Spleen cells from the selected mouse were fused with the myeloma cell line (P3363.Ag8.653., ATCC CRL 1580) at a ratio of 5:1 in the presence of polyethylene glycol (molecular weight, 4000). The hybridoma cells were subsequently diluted to an appropriate density and cultured in hypoxanthine-aminopterinthymidine medium.

The medium was changed twice to remove residual antibodies before the initial screening against flagellin using indirect ELISA. For secondary selection, the positive cells from the initial screening were transferred to larger wells and cultured for three more days. Western blots were performed to confirm the binding to flagellin at $50 \mathrm{kDa}$. The selected cell lines were cloned at least twice by a limiting dilution method and subsequently maintained in liquid nitrogen. Ascites fluids containing the antibodies were obtained from Pristane primed mice 10-14 days after intraperitoneal injection of 
the hybridoma cells. Antibodies were separated from the ascites fluid using a Protein A Cartridge with MAPS II buffer (Bio-Rad). The purified antibodies were dialyzed against PBS overnight at $4{ }^{\circ} \mathrm{C}$ with several changes of dialysis buffer. The concentrations of antibodies in the final preparations were determined by UV absorption at $280 \mathrm{~nm}$. The purified antibodies were stored in aliquote at $-20{ }^{\circ} \mathrm{C}$ with addition $0.05 \%$ of sodium azide. A panel of five monoclonal antibodies (MAbs 1C8, 1E10, 3H8, $5 \mathrm{~F} 11$, and 7E3) was produced. MAbs 1C8, 1E10, and 5F11 belong to $\mathrm{IgG}_{1} ; \mathrm{MAb} 7 \mathrm{E} 3$ and MAb 3H8 belong to $\operatorname{IgG}_{2 a}$ and $\mathrm{IgG}_{2 b}$, respectively, as determined by the Mouse Isotyping Kit (Bio-Rad).

\subsection{Western Blot Assay}

Flagellin preparation was mixed with tripsin at a protein ratio of 10:1 $(w / w)$ and incubated for $2,4,8$, and $16 \mathrm{~min}$ at room temperature. Immediately after incubation for the specified time, the tripsin-treated flagellin was mixed with an equal volume of $2 \times \mathrm{XT}$ loading buffer and heated at $95{ }^{\circ} \mathrm{C}$ for $5 \mathrm{~min}$. An untreated flagellin sample was also prepared with an equal volume of $2 \times \mathrm{XT}$ loading buffer in a similar way. Precision Plus Protein ${ }^{\mathrm{TM}}$ WesternC ${ }^{\mathrm{TM}}$ Standards were used for the molecular weight calibrations. Flagellin samples (untreated and tripsin-treated) and standards were separated using Bolt ${ }^{\mathrm{TM}} 4-12 \%$ Bis-Tris Plus gels. Western blot was carried out on the proteins separated by gel electrophoresis and subsequently transferred to a nitrocellulose membrane. The membrane was blocked overnight with 3\% nonfat dry milk powder in PBST and consecutively incubated with a monoclonal antibody $(0.4 \mu \mathrm{g} / \mathrm{mL}$ in PBST, $1 \%$ BSA) and a goat anti-mouse IgG conjugated to horseradish peroxidase $(0.2 \mu \mathrm{g} / \mathrm{mL}$ in PBST, $1 \%$ BSA). Binding activity was finally detected with Clarity Western ECL substrate prepared according to the manufature's instruction. The image of the blot was generated by the ChemiDoc MP system and analysis of band patterns was completed by using ImageLab software (Bio-Rad, CA, USA).

\subsection{Immobilization of the SPR Sensor Surface}

The 500 kDa Carboxymethyl Dextran Hydrogel Surface Sensor Chip (SR7000 gold sensor slide) was installed onto a Reichert SR7500DC biosensor following the manufacturer's instruction. The sensor surface was then preconditioned by running PBST at $20 \mu \mathrm{L} / \mathrm{min}$ until a stable baseline was obtained. The flow rate of $20 \mu \mathrm{L} / \mathrm{min}$ and temperature of $25^{\circ} \mathrm{C}$ were maintained throughout the immobilization process. In order to activate carboxy groups on the surface of the sensor chip, a fresh preparation of 40 $\mathrm{mg}$ EDC and $10 \mathrm{mg}$ NHS disolved in $1 \mathrm{~mL}$ water was injected onto the sansor surface for $5 \mathrm{~min}$. To the activated surface, MAb 1E10 diluted in $10 \mathrm{mM}$ sodium acetate $(150 \mu \mathrm{g} / \mathrm{mL}), \mathrm{pH} 5.2$, was injected only to the left channel of the surface for $5 \mathrm{~min}$. Then, BSA dissolved in $10 \mathrm{mM}$ sodium acetate $(75 \mu \mathrm{g} / \mathrm{mL})$ was injected to both channels to saturate the remaining active sites. Finally, quenching solution (1.0 $\mathrm{M}$ ethanolamine, $\mathrm{pH}$ 8.5) was injected for $5 \mathrm{~min}$ to deactivate carboxyl groups and to wash away the unbound antibody and BSA. A continuous flow of runing buffer (PBST) at $20 \mu \mathrm{L} / \mathrm{min}$ was maintained after the completion of antibody immobilization. SPR assays were carried out after a stable baseline was achieved.

\subsection{Kinetic Analysis Using SPR}

Kinetic analysis was initiated by injection of flagellin $(17 \mu \mathrm{g} / \mathrm{mL}$ in PBST) onto the MAb 1E10 immobilized sensor surface for $4 \mathrm{~min}$, followed by injection of PBST for $6 \mathrm{~min}$. The binding kinetics of an individual monoclonal antibody to the flagellin captured on the sensor surface was determined from serial dilutions (four different concentrations) of the antibody under study. Each dilution was injected for $4 \mathrm{~min}$ (association) followed by PBST for $6 \mathrm{~min}$ (dissociation). After dissociation, the flagellin-antibody complex was removed from the immobilized surface by injecting regeneration buffer (10 mM Glycine-HCl, $\mathrm{pH}$ 3.0) for $4 \mathrm{~min}$ followed by PBST for $6 \mathrm{~min}$. The same procedures were repeated for the remaining three dilutions of the antibody. After the analyses were completed, signals from left channel were subtracted from signals from their respective reference channel (the right channel). Additionally, the resulting curves were further corrected with a blank signal from the PBST. 
The SPR responses from four concentrations of the same antibody were fitted to a 1:1 bio-interaction model (Langmuir fit model) utilizing TraceDrawer Software. Association rate constant $\left(\mathrm{k}_{\mathrm{a}}\right)$, dissociation rate constant $\left(\mathrm{k}_{\mathrm{d}}\right)$, and maximum binding (Bmax) were fitted globally, whereas the BI signal was fitted locally. The equilibrium dissociation constant $\left(\mathrm{K}_{\mathrm{D}}\right)$ was calculated from the ratio of $\mathrm{k}_{\mathrm{d}} / \mathrm{k}_{\mathrm{a}}$.

\subsection{Pairwise Epitope Mapping Using SPR}

Twenty-five paired combinations from five monoclonal antibodies were used to study the binding inhibition on one antibody due to the other. Initially, flagellin (17 $\mu \mathrm{g} / \mathrm{mL}$ in PBST) was introduced onto the MAb 1E10 immobilized sensor surface for 4 min followed by PBST for 4 min. A pair of antibodies $(11 \mu \mathrm{g} / \mathrm{mL}$ in PBST) were prepared and injected consecutively. The first antibody was injected for $4 \mathrm{~min}$ followed by $4 \mathrm{~min}$ of dissociation, and immediately the second antibody was injected for $4 \mathrm{~min}$, followed by $4 \mathrm{~min}$ of dissociation. Finally, regeneration of the surface was performed by injecting $10 \mathrm{mM}$ Glycine-HCl, pH 3.0, for $4 \mathrm{~min}$ to remove the bound antigen-antibodies complex and to prepare the surface for the next analysis. Experiments were conducted with replicated samples for each pair of monoclonal antibodies. In order to quantify the interference of one antibody binding to another, we compared each of the pairs using the binding ratio as described in a previous report [37]. The binding ratio was defined as the Bmax of the second antibody divided by the Bmax of the first antibody.

\subsection{Data Analysis}

Averages and standard deviations of data from SPR analyses were calculated. Analysis of variance (ANOVA) and multiple comparisons were performed with IBM SPSS Statistics 24 software (Armonk, NY, USA). Tukey's post hoc tests were performed for multiple comparisons.

\section{Results}

\subsection{Limited Proteolysis and Western Blot Analysis}

The results indicated that the undigested flagellin preparations, in addition to the intact flagellin $(50 \mathrm{kDa})$, contain minor fragments in the range between 33 and $41 \mathrm{kDa}$. The presence of flagellin epitopes on these fragments was evident when different monoclonal antibodies were tested. In summary, five anti-flagellin antibodies produced three different banding patterns with undigested flagellin (0 min, Figure 1). MAb 1C8 and MAb 7E3 produced similar banding patterns with one major band at $50 \mathrm{kDa}$ and two minor bands at $38 \mathrm{kDa}$ and $33 \mathrm{kDa}$. Another type of banding pattern, produced by MAb 3H8 and MAb 5F11, had two bands at $50 \mathrm{kDa}$ and $38 \mathrm{kDa}$. Interestingly, MAb $1 \mathrm{E} 10$ produced a unique type of banding pattern. As compared to MAbs 1C8, 7E3, 3H8, and 5F11, MAb 1E10 identified a distinct band at $41 \mathrm{kDa}$. Western blot analysis showed that all five monoclonal antibodies detect at least two bands at $50 \mathrm{kDa}$ and $38 \mathrm{kDa}$.

Proteolytic fragments of flagellin were produced by limited trypsin digestion to compare the different banding patterns of five monoclonal antibodies. Based on the similarity of the banding patterns, these antibodies can be categorized into two groups. MAb 1C8 and MAb 7E3 had similar banding patterns, whereas MAb 3H8, MAb 5F11, and MAb 1 E10 had similar band patterns. All five antibodies detected flagellin fragments at 38, 33, and $23 \mathrm{kDa}$. The results from the Western blot of the trypsin-digested fragments suggested that all epitopes recognized by these five antibodies are collocated within the smallest fragment (23 kDa). MAb 1 C8 and MAb 7E3 detected two additional bands at 27 and $25 \mathrm{kDa}$. Western blot also revealed that there was only one major band at $33 \mathrm{kDa}$ for MAb $1 \mathrm{C} 8$ and MAb 7E3, but for the other three antibodies, there were two major bands at 38 and $33 \mathrm{kDa}$. 


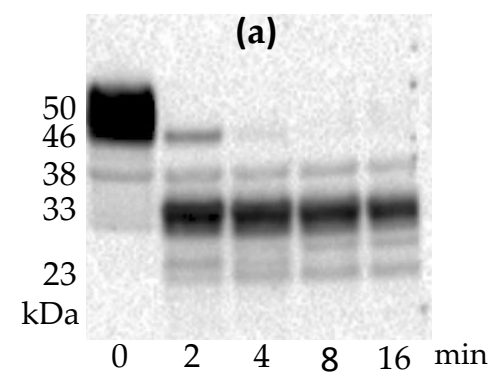

(b)

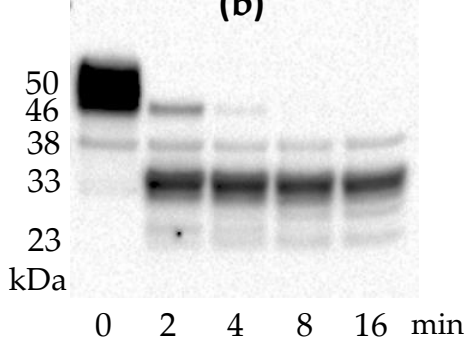

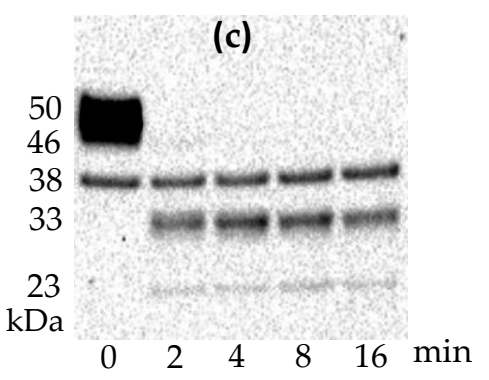

(d)

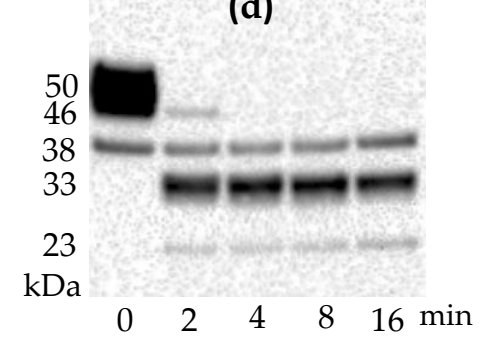

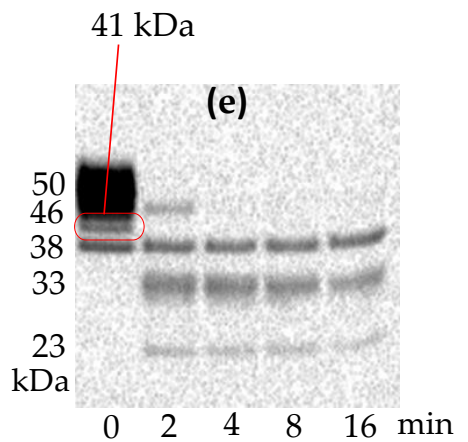

Figure 1. Western blot analysis of undigested flagellin and trypsin-digested flagellin fragments. Flagellin was incubated with trypsin at a protein ratio of 10:1 (w/w) for 2, 4, 8, and 16 min at room temperature. Five different anti-flagellin antibodies, (a) MAb 1C8, (b) MAb 7E3, (c) MAb 3H8, (d) MAb 5F11 and (e) MAb 1E10 were used to detect the flagellin and its fragments. Precision Plus Protein ${ }^{\mathrm{TM}}$ WesternC ${ }^{\mathrm{TM}}$ Standards were used for the molecular weight calibrations.

The results of the Western blot analysis suggested that there were at least three distinct epitopes of flagellin which the five antibodies can react with. The fact that MAb 1E10 was able to bind to a unique size of a flagellin fragment at $41 \mathrm{kDa}$ suggested that the epitope for $1 \mathrm{E} 10$ is different from the rest of the antibodies. Based on this observation, MAb 1E10 was selected as the capturing antibody for the flagellin in the kinetic analysis and epitope mapping.

\subsection{The Binding Kinetics of Monoclonal Antibodies to Flagellin}

A typical sensorgram of the interactions of four different concentrations of the same antibody to the flagellin captured by MAb 1E10 immobilized on the sensor surface is presented in Figure 2. SPR curves were fitted to a 1:1 interaction model. Finally, the association rate constant $\left(k_{a}\right)$, dissociation rate constant $\left(k_{d}\right)$, and the equilibrium dissociation constant $\left(K_{\mathrm{D}}\right)$ of the antibody were determined. The kinetic data of four monoclonal antibodies are summarized in Table 1.

Table 1. Kinetic parameters of four monoclonal antibodies to S. Typhimurium flagellin.

\begin{tabular}{llll}
\hline Antibodies & $\boldsymbol{k}_{\boldsymbol{a}}\left(\mathbf{M}^{-\mathbf{1}} \mathbf{s}^{-\mathbf{1}}\right)$ & $\boldsymbol{k}_{\boldsymbol{d}}\left(\mathbf{s}^{-\mathbf{1}}\right)$ & $\boldsymbol{K}_{\mathbf{D}} \mathbf{( M )}$ \\
\hline MAb 1C8 & $6.43 \times 10^{5 \mathrm{~b}}\left( \pm 5.23 \times 10^{4}\right)$ & $7.09 \times 10^{-5 \mathrm{ab}}\left( \pm 3.55 \times 10^{-5}\right)$ & $1.13 \times 10^{-10 \mathrm{ab}}\left( \pm 6.41 \times 10^{-11}\right)$ \\
MAb 7E3 & $4.88 \times 10^{5 \mathrm{~b}}\left( \pm 9.26 \times 10^{4}\right)$ & $1.03 \times 10^{-4 \mathrm{ab}}\left( \pm 1.53 \times 10^{-5}\right)$ & $2.19 \times 10^{-10 \mathrm{ab}}\left( \pm 7.28 \times 10^{-11}\right)$ \\
MAb 3H8 & $6.68 \times 10^{5 \mathrm{~b}}\left( \pm 6.36 \times 10^{3}\right)$ & $2.17 \times 10^{-4 \mathrm{a}}\left( \pm 4.45 \times 10^{-5}\right)$ & $3.25 \times 10^{-10 \mathrm{a}}\left( \pm 7.00 \times 10^{-11}\right)$ \\
MAb 5F11 & $1.57 \times 10^{6 \mathrm{a}}\left( \pm 9.19 \times 10^{4}\right)$ & $3.98 \times 10^{-5 \mathrm{~b}}\left( \pm 4.74 \times 10^{-5}\right)$ & $2.63 \times 10^{-11 \mathrm{~b}}\left( \pm 3.18 \times 10^{-11}\right)$ \\
\hline Average & $8.41 \times 10^{5}\left( \pm 4.56 \times 10^{5}\right)$ & $1.08 \times 10^{-4}\left( \pm 7.69 \times 10^{-5}\right)$ & $1.70 \times 10^{-10}\left( \pm 1.29 \times 10^{-10}\right)$ \\
$p$-value & 0.00 & 0.034 & 0.031 \\
\hline
\end{tabular}

The numbers followed by different letters are significantly different; the values in parentheses are standard deviations. 


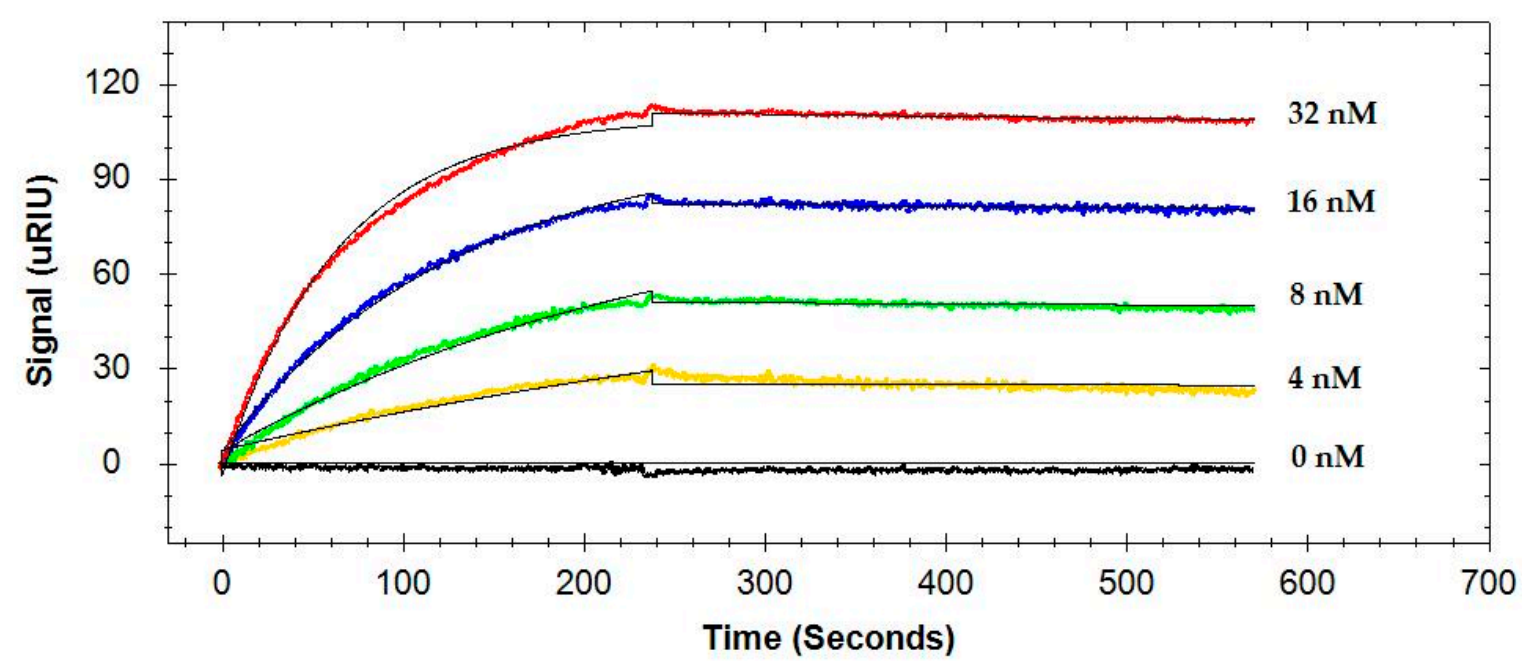

Figure 2. A representative sensorgram showing the interactions of four concentrations of the same antibody (MAb 7E3) to the flagellin captured on the sensor surface by immobilized MAb 1E10.

The flagellin was first captured by MAb 1E10 immobilized on the sensor surface, and four concentrations of the same antibody were analyzed consecutively. The 1:1 interaction model was used, and the association rate constant $\left(k_{a}\right)$, dissociation rate constant $\left(k_{d}\right)$, and the equilibrium dissociation constant $\left(K_{\mathrm{D}}\right)$ were calculated. Values in parentheses are standard deviations. ANOVA was performed to determine the significant difference. A Tukey's post-hoc test was performed for multiple comparisons, and numbers followed by different letters were significantly different.

It was found that four antibodies differ significantly $(p<0.05)$ for their association rate $\left(k_{a}\right)$, dissociation rate $\left(k_{d}\right)$, and the equilibrium dissociation constant $\left(K_{\mathrm{D}}\right)$ based on their interactions with the flagellin captured by MAb 1E10 (Table 1). MAb 5F11 had a faster association rate and was 2.4, 3.2, and 2.3-fold higher than MAb 1C8, MAb 7E3, and MAb 3H8, respectively. MAb 1C8, MAb 7E3, and $\mathrm{MAb} 3 \mathrm{H} 8$ showed no significant difference in their association rates.

The dissociation rate $\left(k_{d}\right)$ and equilibrium dissociation constant $\left(K_{\mathrm{D}}\right)$ of $\mathrm{MAb} 3 \mathrm{H} 8$ were significantly different from that of MAb 5F11. However, the $k_{d}$ and $K_{\mathrm{D}}$ values of MAb $1 \mathrm{C} 8$ and $\mathrm{MAb} 7 \mathrm{E} 3$ were not significantly different. MAb 3H8 had a faster dissociation, which was 3.1, 2.1, and 5.4-fold higher than MAb 1C8, MAb 7E3, and MAb 5F11, respectively. As a result, MAb 3H8 had the lowest affinity as indicated by the highest $K_{\mathrm{D}}$ with flagellin, and its value was $2.9,1.5$, and 12.3-fold higher than that of MAb 1C8, MAb 7E3, and MAb 5F11, respectively.

\subsection{Epitope Mapping by SPR Inhibition Assay}

The relative positions of flagellin epitopes between a pair of monoclonal antibodies were studied using the SPR inhibition assay which measures the competitive binding of one antibody due to the previous binding of another antibody. Typical examples of the inhibition/non-inhibition of the binding of an antibody to another are illustrated in Figure 3. At first, flagellin was captured by MAb 1E10 immobilized on the sensor surface. The average binding response of flagellin to the immobilized MAb $1 \mathrm{E} 10$ was 137 micro-Refractive Index Units ( $\mu$ RIU). Immediately after, MAb 1C8 was injected and MAb $3 \mathrm{H} 8$ was followed. MAb 3H8 bound with the flagellin and yielded a comparable SPR signal to MAb 1C8 (Bmax 250 and $255 \mu$ RIU, respectively). It indicated that MAb 1C8 has no inhibition on the binding of MAb 3H8. In a completely opposite case, after MAb 1C8, MAb 7E3 was injected. MAb 7E3 did not bind to the flagellin $(0 \mu \mathrm{RIU})$. It indicated that the binding of MAb 7E3 was completely inhibited by MAb 1C8. 
(a)

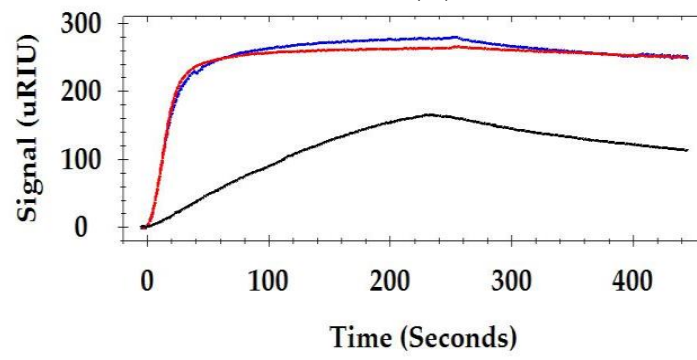

(b)

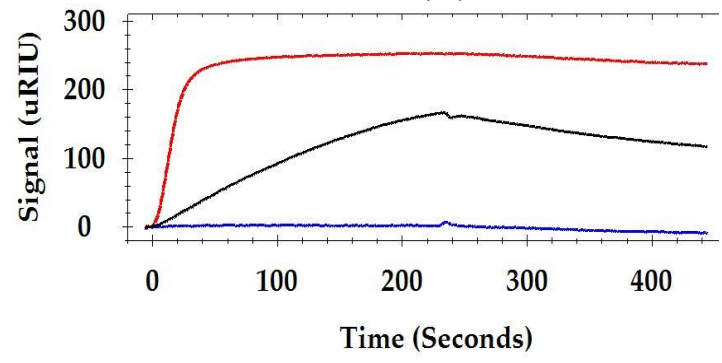

Figure 3. Representative SPR sensorgrams showing (a) non-inhibition and (b) inhibition of the binding of a pair of monoclonal antibodies; (a) Flagellin (black curve) was captured by MAb 1E10 immobilized on the surface. Immediately after the flagellin, MAb 1C8 (red curve) was injected and MAb 3H8 (blue curve) was followed after. Both MAbs (1C8 and 3H8) produced binding curves (non-inhibition); (b) Flagellin (black curve) was captured by MAb 1 E10 immobilized on the surface. Immediately after the flagellin, MAb 1C8 (red curve) was injected and MAb 7E3 (blue curve) was followed after. MAb 7E3 failed to produce a binding curve (inhibition).

The inhibition of the binding was calculated as the binding ratio by dividing the Bmax of the second antibody with the Bmax of the first antibody. A summary of the binding ratio of paired monoclonal antibodies on the immobilized flagellin is presented in Table 2. Antibody binding ratios of approximately $<1,=1$ and $>1$ were expected for binding inhibition, no binding inhibition, and binding enhancement, respectively. The binding ratios revealed that the same antibody injected consecutively one after another did not produce a binding signal during the second injection except in the case of two antibodies. MAb $3 \mathrm{H} 8$ and MAb 5F11 produced approximately $20 \%$ and $21 \%$ binding signals in the second injection as compared to their first injection.

Table 2. Summary of the binding ratios of paired monoclonal antibodies on the immobilized flagellin.

\begin{tabular}{lllll}
\hline \multirow{2}{*}{ First MAb } & \multicolumn{4}{c}{ Second MAb } \\
\cline { 2 - 5 } & MAb 1C8 & MAb 7E3 & MAb 3H8 & MAb 5F11 \\
\hline MAb 1C8 & $0.06( \pm 0.01)$ & $0.29( \pm 0.02)$ & $1.76( \pm 0.48)$ & $1.72( \pm 0.07)$ \\
MAb 7E3 & $0.12( \pm 0.00)$ & $0.03( \pm 0.01)$ & $2.02( \pm 0.01)$ & $2.19( \pm 0.23)$ \\
MAb 3H8 & $1.65( \pm 0.11)$ & $1.06( \pm 0.01)$ & $0.20( \pm 0.04)$ & $1.53( \pm 0.08)$ \\
MAb 5F11 & $1.04( \pm 0.06)$ & $1.31( \pm 0.02)$ & $1.49( \pm 0.43)$ & $0.21( \pm 0.03)$ \\
\hline
\end{tabular}

The binding ratio was obtained by dividing the maximum binding (Bmax) of second antibody to the Bmax of first antibody; the values in parentheses are standard deviations.

Interestingly, it was found that antibody pairs (MAb 1C8 and MAb 7E3) interfered with the binding of each other. The data suggested that MAb 7E3 and MAb 1C8 have an identical epitope or overlapping epitopes. The binding ratio of MAb 1C8 after binding of MAb 7E3 was 0.12, whereas the ratio of MAb 7E3 after binding of MAb 1C8 was 0.29. In other words, the binding of MAb 7E3 had reduced the binding of $\mathrm{MAb} 1 \mathrm{C} 8$ by $88 \%$, and in contrast, the binding of MAb $1 \mathrm{C} 8$ had reduced the binding of MAb 7E3 by 71\%.

On the other hand, pairs of monoclonal antibodies that have a binding ratio of equal to or more than 1.0 indicate either no inhibition or enhancement of binding by the previously injected antibody. There are several cases where enhancement of the binding of the secondary antibody was observed. This may be attributed to the differences of the affinities between the two antibodies and the conformational changes of flagellin caused by the binding of the first antibody [46]. Collectively, it was clear that the first antibody did not hinder the binding of the second antibody except in the case of MAb 1C8 and MAb 7E3.

There was no binding response $(0 \mu \mathrm{RIU})$ when the same MAb $1 \mathrm{E} 10$ was injected after flagellin was captured by the immobilized MAb 1E10. It suggested that the binding of 1E10 to flagellin was univalent 
and all binding sites of MAb 1E10 were fully occupied by the immobilized MAb 1E10 (the capturing antibody). However, antibodies injected after MAb 1E10 produced signals with no inhibition. It was clear that MAb 1E10 did not hinder the binding of other antibodies when injected consequently.

\section{Discussion}

Western blot analysis showed that five monoclonal antibodies detected three types of banding patterns with undigested flagellin. After limited trypsin digestion, two types of banding patterns were observed. The presence of minor fragments in the undigested flagellin was noticed in the range between $38-41 \mathrm{kDa}$. Smaller fragments $(41,42 \mathrm{kDa})$ of $S$. Typhimurium flagellin due to the deletion of parts of the outer domain have been reported previously [47].

Of the five monoclonal antibodies, only MAb $1 \mathrm{E} 10$ was able to detect the $41 \mathrm{kDa}$ fragments, indicating the epitope of 1E10 is distinctly different from the rest of the antibodies. Based on this observation, MAb 1E10 was selected as the capturing antibody of the flagellin for pairwise comparisons of the other four antibodies. In contrast to the covalent immobilization of flagellin directly on the sensor surface, the immobilization of flagellin through the epitope of MAb 1E10 allowed other epitopes to be presented in a precise orientation and to be evaluated relative to the epitope of MAb $1 E 10$. This approach also avoided the potential epitopes hindrance by covalent immobilization of the flagellin directly on the sensor surface and allowed for the comparison of more than two potential epitopes concurrently. In a previous report, liposomes were used to immobilize anti-flagellin antibodies for epitope mapping and kinetic analysis [44]. Our approach of immobilizing flagellin through an epitope using a capturing monoclonal antibody has not been reported elsewhere.

We have investigated five anti-flagellin antibodies to determine the epitope map using pairwise SPR assays. From the binding ratios (Table 2), it can be concluded that there are at least four epitopes recognized by the five different antibodies. A diagram of the four hypothesized epitopes of flagellin is presented in Figure 4. These conformational epitopes, centered by the epitope of MAb 1E10, are separated by a distance, and therefore, there is no interference with the binding of each other.

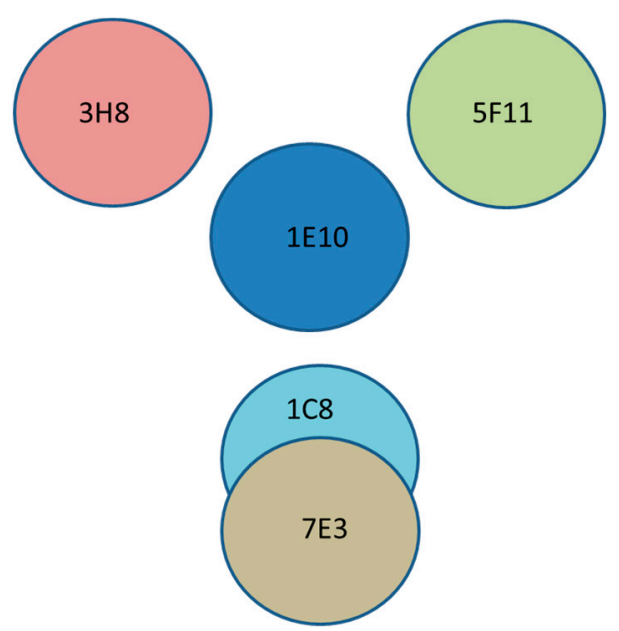

Figure 4. A diagram of conformational epitopes of flagellin centered by the epitope of MAb 1E10. Four distinct epitopes were identified using five anti-flagellin antibodies (MAb 3H8, MAb 5F11, MAb 1C8, $\mathrm{MAb} 7 \mathrm{E} 3$, and MAb 1E10). Overlapping circles denote common epitopes shared by MAb 1C8 and MAb 7E3.

Western blot of the trypsin-digested fragments suggested that these epitopes are located within a domain of $23 \mathrm{kDa}$ on flagellin. Our results were coincident with the findings of other studies. Four distinct flagellin epitopes of Salmonella Muenchen were described using octameric peptides synthesized on polyethylene pins [48]. It has been proposed from other researchers [47] that there are three domains in flagellin, D1-D3, from the center of the filament axis outwards in the radial direction. 
The core domain (D1) is responsible for filament assembly and polymorphism. The middle domain (D2) may be related to the stability of the filament shape. The outer domains (D3) of adjacent subunits in a filament are not connected to each other. There are several lines of evidence showing that the exposed D3 domain contains the major epitopes of the flagellar antigen ( $\mathrm{H}$ antigen). Other studies have provided evidence of the presence of discontinuous flagellin epitopes [8], and it was suggested that a minimal area, 86 amino acids for $\mathrm{H}: \mathrm{i}$ and 102 amino acids for $\mathrm{H}: 1,2$, located in the central variable domain of each flagellin, was required for the binding of serotype-specific antibodies. In addition, there are some epitopes that may be shared by phase- 1 and phase- 2 flagellin. A previous study using ELISA-based epitope mapping has shown only one binding site on the recombinant flagellin of $S$. Typhimurium, where researchers investigated 6 antibodies, 3 for phase- 1 and 3 for phase- 2 flagellin [8].

Binding kinetics are crucial for the applications of these monoclonal antibodies in detection and subtyping studies. All antibodies significantly differ in terms of association rate, dissociation rate, and the equilibrium dissociation constant. We have compared several approaches to fitting the kinetic data; the best fittings were achieved using a 1:1 interaction model (Langmuir fit model). It should be noted that the presence of minor fragments in the flagellin preparations could affect the fitting and cause a small deviation from the 1:1 interaction model and may consequently contribute to slightly higher variations in the kinetic parameters. Nevertheless, this is the first study reporting on the kinetics of more than one anti-flagellin antibody with the captured flagellin of $S$. Typhimurium.

\section{Conclusions}

We have demonstrated a real-time and label-free epitope mapping of Salmonella flagellin with SPR using a panel of anti-flagellin antibodies. With the epitope-captured-flagellin approach, four separated epitopes were identified by the five monoclonal antibodies. In addition, results from the Western blot of trypsin-digested fragments indicated all four epitopes are located within a $23 \mathrm{kDa}$ domain of the flagellin. Collectively, epitope mapping and kinetics data obtained in this study are crucial for the further development and optimization of SPR and other immunoassays for the detection and subtyping of Salmonella. Based on the results of this study, SPR assays utilizing magnetic nanoparticle coupled monoclonal antibodies to enhance the sensitivity for the detection of Salmonella in food and environmental samples are being developed.

Author Contributions: Conceptualization, methodology, software, and validation, D.B. and F.-C.C.; formal analysis, D.B.; investigation, D.B. and F.-C.C.; resources, R.C.B. and F.-C.C.; data curation, D.B. and S.H.; writing-original draft preparation, D.B.; writing-review and editing, F.-C.C.; visualization, D.B.; supervision, F.-C.C.; project administration, F.-C.C.; funding acquisition, F.-C.C.

Funding: This research was funded by United States Department of Agriculture, National Institute of Food and Agriculture; project number TENX-1812-FS.

Conflicts of Interest: The authors declare no conflict of interest.

\section{References}

1. Galanis, E.; Lo Fo Wong, D.M.A.; Patrick, M.E.; Binsztein, N.; Cieslik, A.; Chalermchikit, T.; Aidara-Kane, A.; Ellis, A.; Angulo, F.J.; Wegener, H.C.; et al. Web-based surveillance and global Salmonella distribution, 2000-2002. Emerg. Infect. Dis. 2006, 12, 381-388. [CrossRef] [PubMed]

2. Blair, D.F. How Bacteria Sense and Swim. Annu. Rev. Microbiol. 1995, 49, 489-520. [CrossRef] [PubMed]

3. Aizawa, S.-I. Flagellar assembly in Salmonella typhimurium. Mol. Microbiol. 1996, 19, 1-5. [CrossRef] [PubMed]

4. Zieg, J.; Silverman, M.; Hilmen, M.; Simon, M. Recombinational switch for gene expression. Science 1977, 196, 170-172. [CrossRef] [PubMed]

5. Silverman, M.; Zieg, J.; Hilmen, M.; Simon, M. Phase variation in Salmonella: Genetic analysis of a recombinational switch. Proc. Natl. Acad. Sci. USA 1979, 76, 391-395. [CrossRef] [PubMed]

6. Grimont, P.; Weill, F. Antigenic Formulae of the Salmonella Serovars; WHO: Geneva, Switzerland; Institut Pasteur: Paris, France, 2007; pp. 1-166. 
7. Bonifield, H.R.; Hughes, K.T. Flagellar phase variation in Salmonella enterica is mediated by a posttranscriptional control mechanism. J. Bacteriol. 2003, 185, 3567-3574. [CrossRef] [PubMed]

8. De Vries, N.; Zwaagstra, K.A.; Huis in't Veld, J.H.; van Knapen, F.; van Zijderveld, F.G.; Kusters, J.G. Production of monoclonal antibodies specific for the i and 1,2 flagellar antigens of Salmonella typhimurium and characterization of their respective epitopes. Appl. Environ. Microbiol. 1998, 64, 5033-5038. [PubMed]

9. Crowe, J.E., Jr.; Smith, S.A. Use of human hybridoma technology to isolate human monoclonal antibodies. Microbiol. Spectr. 2015, 3, 141-156.

10. Zhang, C. Hybridoma Technology for the Generation of Monoclonal Antibodies; Humana Press: Totowa, NJ, USA, 2012; pp. 117-135.

11. Cambra, M.; Asensio, M.; Gorris, M.T.; Perez, E.; Camarasa, E.; Garcia, J.A.; Moya, J.J.; Lopez-Abella, D.; Vela, C.; Sanz, A. Detection of plum pox potyvirus using monoclonal antibodies to structural and non-structural proteins. EPPO Bull. 1994, 24, 569-577. [CrossRef]

12. Morgan, G.; Levinsky, R.J. Monoclonal antibodies in diagnosis and treatment. Arch. Dis. Child. 1985, 60, 96-98.

13. Yang, X.D.; Jia, X.C.; Corvalan, J.R.; Wang, P.; Davis, C.G. Development of ABX-EGF, a fully human anti-EGF receptor monoclonal antibody, for cancer therapy. Crit. Rev. Oncol. Hematol. 2001, 38, 17-23. [CrossRef]

14. Witte, L.; Hicklin, D.J.; Zhu, Z.; Pytowski, B.; Kotanides, H.; Rockwell, P.; Böhlen, P. Monoclonal antibodies targeting the VEGF receptor-2 (Flk1/KDR) as an anti-angiogenic therapeutic strategy. Cancer Metastasis Rev. 1998, 17, 155-161. [CrossRef] [PubMed]

15. Nalbantsoy, A.; Karaboz, I.; Gurhan, I.D. Production of monoclonal antibody against Salmonella H: G,m flagellar antigen and potential diagnostic application. Hybridoma 2010, 29, 419-423. [CrossRef] [PubMed]

16. Qadri, A.; Ghosh, S.; Upadhyay, S.; Talwar, G.P. Monoclonal antibodies against flagllar antigen of Salmonella typhi. Hybridoma 1989, 8, 353-360. [CrossRef] [PubMed]

17. Rementeria, A.; Vivanco, A.B.; Ramirez, A.; Hernando, F.L.; Bikandi, J.; Herrera-León, S.; Echeita, A.; Garaizar, J. Characterization of a monoclonal antibody directed against Salmonella enterica serovar Typhimurium and serovar [4,5,12:i:-]. Appl. Environ. Microbiol. 2009, 75, 1345-1354. [CrossRef] [PubMed]

18. Hiriart, Y.; Serradell, M.; Martínez, A.; Sampaolesi, S.; Maciel, D.; Chabalgoity, J.; Yim, L.; Algorta, G.; Rumbo, M. Generation and selection of anti-flagellin monoclonal antibodies useful for serotyping Salmonella enterica. Springerplus 2013, 2, 640. [CrossRef] [PubMed]

19. Sadallah, F.; Brighouse, G.; del Giudice, G.; Drager-Dayal, R.; Hodne, M.; Lambert, P.H. Production of specific monoclonal antibodies to salmonella typhi flagellin and possible application to immunodiagnosis of typhoid fever. J. Infect. Dis. 1990, 161, 59-64. [CrossRef] [PubMed]

20. Ibrahim, G.F.; Fleet, G.H.; Lyons, M.J.; Walker, R.A. Method for the isolation of highly purified Salmonella flagellins. J. Clin. Microbiol. 1985, 22, 1040-1044. [PubMed]

21. Liu, Y.; Che, Y.; Li, Y. Rapid detection of Salmonella Typhimurium using immunomagnetic separation and immuno-optical sensing method. Sensors Actuators B Chem. 2001, 72, 214-218. [CrossRef]

22. Brigmon, R.L.; Zam, S.G.; Bitton, G.; Farrah, S.R. Detection of Salmonella Enteritidis in environmental samples by monoclonal antibody-based ELISA. J. Immunol. Methods 1992, 152, 135-142. [CrossRef]

23. Beumer, R.R.; Brinkman, E.; Rombouts, F.M. Enzyme-linked immunoassays for the detection of Salmonella spp.: A comparison with other methods. Int. J. Food Microbiol. 1991, 12, 363-374. [CrossRef]

24. Eriksson, E.; Aspan, A. Comparison of culture, ELISA and PCR techniques for Salmonella detection in faecal samples for cattle, pig and poultry. BMC Vet. Res. 2007, 3, 21. [CrossRef] [PubMed]

25. Bokken, G.C.A.M.; Corbee, R.J.; Knapen, F.; Bergwerff, A.A. Immunochemical detection of Salmonella group B, D and E using an optical surface plasmon resonance biosensor. FEMS Microbiol. Lett. 2003, 222, 75-82. [CrossRef]

26. Lan, Y.-B.; Wang, S.-Z.; Yin, Y.-G.; Hoffmann, W.C.; Zheng, X.-Z. Using a surface plasmon resonance biosensor for rapid detection of Salmonella Typhimurium in chicken carcass. J. Bionic Eng. 2008, 5, 239-246. [CrossRef]

27. Oh, B.-K.; Kim, Y.-K.; Park, K.W.; Lee, W.H.; Choi, J.-W. Surface plasmon resonance immunosensor for the detection of Salmonella Typhimurium. Biosens. Bioelectron. 2004, 19, 1497-1504. [CrossRef] [PubMed]

28. Taylor, A.D.; Ladd, J.; Yu, Q.; Chen, S.; Homola, J.; Jiang, S. Quantitative and simultaneous detection of four foodborne bacterial pathogens with a multi-channel SPR sensor. Biosens. Bioelectron. 2006, 22, 752-758. [CrossRef] [PubMed] 
29. Mazumdar, S.D.; Barlen, B.; Kämpfer, P.; Keusgen, M. Surface plasmon resonance (SPR) as a rapid tool for serotyping of Salmonella. Biosens. Bioelectron. 2010, 25, 967-971. [CrossRef] [PubMed]

30. Homola, J.; Yee, S.S.; Gauglitz, G. Surface plasmon resonance sensors: Review. Sensors Actuators B Chem. 1999, 54, 3-15. [CrossRef]

31. Homola, J. Present and future of surface plasmon resonance biosensors. Anal. Bioanal. Chem. 2003, 377, 528-539. [CrossRef] [PubMed]

32. Jinn-Nan, L.; I-Nan, C.; Andrade, J.D.; Herron, J.N.; Christensen, D.A. Comparison of site-specific coupling chemistry for antibody immobilization on different solid supports. J. Chromatogr. A 1991, 542, 41-54. [CrossRef]

33. Brunel, F.M.; Zwick, M.B.; Cardoso, R.M.F.; Nelson, J.D.; Wilson, I.A.; Burton, D.R.; Dawson, P.E. Structure-function analysis of the epitope for 4E10, a broadly neutralizing human immunodeficiency virus type 1 antibody. J. Virol. 2006, 80, 1680-1687. [CrossRef] [PubMed]

34. Daiss, J.L.; Scalice, E.R. Epitope mapping on biacore: Theoretical and practical considerations. Methods 1994, 6, 143-156. [CrossRef]

35. Dubs, M.-C.; Altschuh, D.; Van Regenmortel, M.H.V. Mapping of viral epitopes with conformationally specific monoclonal antibodies using biosensor technology. J. Chromatogr. A 1992, 597, 391-396. [CrossRef]

36. Fägerstam, L.G.; Frostell, Å.; Karlsson, R.; Kullman, M.; Larsson, A.; Malmqvist, M.; Butt, H. Detection of antigen—antibody interactions by surface plasmon resonance. Application to Epitope Mapping. J. Mol. Recognit. 1990, 3, 208-214. [CrossRef] [PubMed]

37. Thomsen, L.; Gurevich, L. A surface plasmon resonance assay for characterisation and epitope mapping of anti-GLP-1 antibodies. J. Mol. Recognit. 2018, e2711. [CrossRef] [PubMed]

38. Canziani, G.A.; Klakamp, S.; Myszka, D.G. Kinetic screening of antibodies from crude hybridoma samples using Biacore. Anal. Biochem. 2004, 325, 301-307. [CrossRef] [PubMed]

39. Christensen, L.H.; Holm, J.; Lund, G.; Riise, E.; Lund, K. Several distinct properties of the IgE repertoire determine effector cell degranulation in response to allergen challenge. J. Allergy Clin. Immunol. 2008, 122, 298-304. [CrossRef] [PubMed]

40. Fisher, R.J.; Fivash, M. Surface plasmon resonance based methods for measuring the kinetics and binding affinities of biomolecular interactions. Curr. Opin. Biotechnol. 1994, 5, 389-395. [CrossRef]

41. Gupta, G.; Sharma, P.K.; Sikarwar, B.; Merwyn, S.; Kaushik, S.; Boopathi, M.; Agarwal, G.S.; Singh, B. Surface plasmon resonance immunosensor for the detection of Salmonella typhi antibodies in buffer and patient serum. Biosens. Bioelectron. 2012, 36, 95-102. [CrossRef] [PubMed]

42. Johne, B.; Gadnell, M.; Hansen, K. Epitope mapping and binding kinetics of monoclonal antibodies studied by real time biospecific interaction analysis using surface plasmon resonance. J. Immunol. Methods 1993, 160, 191-198. [CrossRef]

43. Malmqvist, M. Surface plasmon resonance for detection and measurement of antibody-antigen affinity and kinetics. Curr. Opin. Immunol. 1993, 5, 282-286. [CrossRef]

44. Olguín, Y.; Villalobos, P.; Carrascosa, L.G.; Young, M.; Valdez, E.; Lechuga, L.; Galindo, R. Detection of flagellin by interaction with human recombinant TLR5 immobilized in liposomes. Anal. Bioanal. Chem. 2013, 405, 1267-1281. [CrossRef] [PubMed]

45. Säfsten, P.; Klakamp, S.L.; Drake, A.W.; Karlsson, R.; Myszka, D.G. Screening antibody-antigen interactions in parallel using Biacore A100. Anal. Biochem. 2006, 353, 181-190. [CrossRef] [PubMed]

46. Vanegas, R.A.; Joys, T.M. Molecular analyses of the phase-2 antigen complex 1,2,.. of Salmonella spp. J. Bacteriol. 1995, 177, 3863-3864. [CrossRef] [PubMed]

47. Yoshioka, K.; Aizawa, S.I.; Yamaguchi, S. Flagellar filament structure and cell motility of Salmonella typhimurium mutants lacking part of the outer domain of flagellin. J. Bacteriol. 1995, 177, 1090-1093. [CrossRef] [PubMed]

48. Joys, T.M.; Schödel, F. Epitope mapping of the d flagellar antigen of Salmonella muenchen. Infect. Immun. 1991, 59, 3330-3332. [PubMed]

(C) 2019 by the authors. Licensee MDPI, Basel, Switzerland. This article is an open access article distributed under the terms and conditions of the Creative Commons Attribution (CC BY) license (http:/ / creativecommons.org/licenses/by/4.0/). 